\title{
Poland syndrome: Chest wall and breast repair
}

\author{
Charilaos loannidis
}

laso General Hospital, Athens, Greece

\section{Corresponding Author}

Charilaos loannidis, Consultant P/R Surgeon UCL Hospitals, Assoc. Professor of Surgery, University of Leuven (B), 18 loannou Gennadiou, 11521 Athens, Greece, 0030210 7242109, e-mail: ioannidc@otenet.gr

\section{Abstract}

Introduction: Poland syndrome is a rare congenital disorder. Its main characteristics are deficiency of the sternocostal portion of the pectoralis major muscle and symbrachydactyly. However, it encompasses a wide spectrum of other chest, breast and upper extremity anomalies. Patients and Methods: The author's personal experience with a small series of patients with Poland syndrome is retrospectively reviewed. Only chest and breast anomalies were surgically corrected. A bilateral augmentation mammoplasty using different size implants was performed in order to restore chest and breast asymmetry in female patients. The latissimus dorsi muscle was transferred in order to replace the absent pectoralis major in male patients. Results: Eleven adult patients were found. There were 8 female and 3 male patients (age 21-29, mean 23,5y). Two patients refused any kind of treatment. Nine patients (six females, three males) underwent surgical correction (right side $n=8$, left side $n=1$ ). The follow-up period ranged from 6 months to 14 years. There were no major complications. There was a minor complication (seroma) in a male patient after latissimus dorsi transfer, which resolved spontaneously. No capsular contracture has been detected to date and no revision or implant change has been necessary in any of the female patients. All patients were satisfied with the final outcome. Conclusions: The pedicled latissimus dorsi muscle is still the "golden standard" for replacement of the totally absent pectoralis major muscle especially in males. Breast implants are highly successful in correcting chest/ breast asymmetry (size and shape anomalies) in females. Remaining nipple/areola deformities can be easily tackled at a later stage.

Key words: Poland syndrome/sequence/anomaly, pectoralis major muscle deficiency, latissimus dorsi muscle flap, customized chest implants, breast implants, congenital hand anomaly, syndactyly, brachydactyly

\section{Introduction}

Poland syndrome, also termed Poland sequence or Poland anomaly, is a rare congenital disorder. It encompasses a number of features, including altera- tions in the ipsilateral thorax and upper extremity, and other malformations. The classic description of the syndrome was published in 1841 by Alfred Po- 
land, a 19-year old medical student at Guy's Hospital in London, England ${ }^{1}$, and was based on the autopsy of a 27-year old male convict. Poland described deficiency of the sternal and costal portion of the pectoralis major muscle, absent middle phalanges of the ipsilateral hand and a web between the fingers which extended to the first articulation ${ }^{1}$. Clarkson, a plastic surgeon at Guy's Hospital, coined the eponym Poland's syndactyly ${ }^{2}$ and Baudinne later referred to the complex as Poland syndrome ${ }^{3}$.

Partial or complete lack of the pectoralis major muscle is the characteristic of Poland syndrome. Furthermore, deformities of skeletal and muscular structures of the rib cage and of the breast and nipple/areola may be present ${ }^{4,5}$. The most common hand anomaly is partial or complete symbrachydactyly, but abnormalities may range from simple syndactyly to complete ectrodactyly (absence of digits). In addition, polydactyly, absence or hypoplasia of carpal bones or metacarpals, absence or attenuation of flexor or extensor tendons, shortening of the radius, the ulna or the humerus and nail agenesis have been described ${ }^{6}$. Other abnormalities are more rarely associated with Poland syndrome and include Moebius syndrome, Klippel-Feil syndrome, renal anomalies, dextrocardia, leukemia, non-Hodgkin lymphoma and others ${ }^{7}$. Romanini et $\mathrm{al}^{5}$ proposed a new classification of Poland syndrome thoracic malformations: Thoracic: T1(Hypoplasia or aplasia of pectoralis major muscles and soft tissue)-T2(T1 and sternal deformity, pectus excavatum and/or carinatum)-T3(T1 and rib aplasia)-T4(T1,T2,and T3-muscle,sternum, and rib defects); Breast: B1(Breast hypoplasia)- B2(Breast aplasia); Nipple/areola complex: N1(NAC hypoplasia with dislocation of $<2 \mathrm{~cm}$ )-N2(NAC hypoplasia with dislocation of $>2 \mathrm{~cm}$ )-N3 (Absent NAC).

Because of the variability in presentation, Poland syndrome is oftentimes undiagnosed at birth. Milder forms of the disease evade detection until late adolescence and puberty ${ }^{8}$. Identifying all clini- cal manifestations of the syndrome, however, is an important aspect of diagnosis and may ultimately lead to better treatment ${ }^{9}$. Hand anomalies cause functional disability and are corrected early in life. The chest/breast deformity does not cause functional impairment to the majority of patients; corrective operations are largely cosmetic and aim at restoring thoracic, breast and nipple/areola complex symmetry. They are usually performed in adult life. The purpose of the present study is to review the author's personal experience and present the results of chest wall and breast reconstruction in eleven patients with Poland syndrome.

\section{Patients and Methods}

Patients for this study were selected from women and men who sought consultation, and treatment, for breast asymmetry and anterior chest wall deformities. A thorough history followed by clinical examination was performed in all patients. The chest was inspected and palpated for degree of depression or anterior projection. The breasts were evaluated for shape, size and position of the nipple-areola complex. The posterior thorax was inspected for abnormal development and elevation of the scapula (Sprengel deformity) or presence of scoliosis. The upper extremity was examined for any congenital malformations. A CT and/or MRI scan of the chest was performed in all patients (Figure 1). Photographs of all patients were taken.

A number of patients opted for no treatment. The remaining underwent correction of the anterior chest wall with a pedicled latissimus dorsi muscle flap (males) and the chest/ breast deficiency with an augmentation mammoplasty (females). The latter was performed bilaterally, when indicated, using implants of different size (pathological side $>$ ), and achieved correction of the chest wall depression, augmentation of the overlying breast improving its shape and matching, as best as possible, the (aug- 

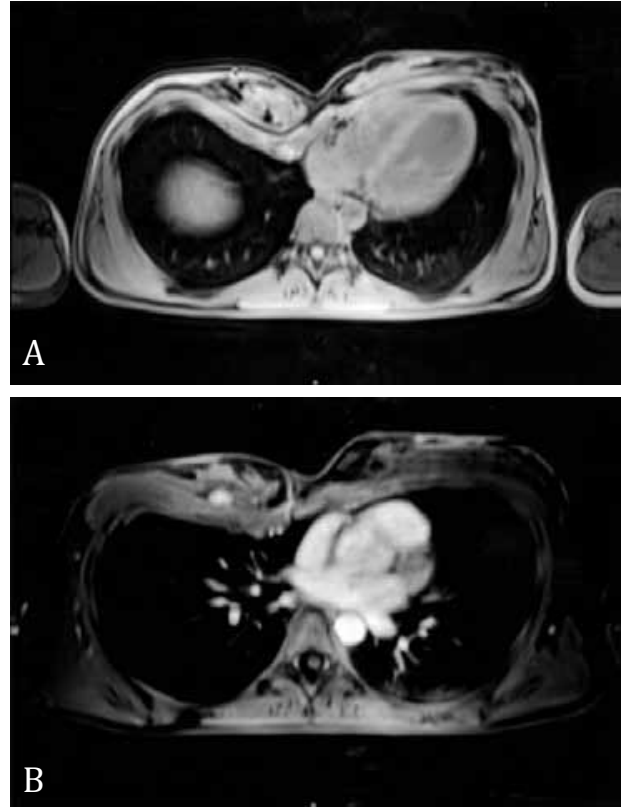

Figure 1. MRI of a patient with right Poland syndrome. A. The chest and breast asymmetry is clearly visible. B. A 1.6 $\mathrm{cm}$ large neoplasm with benign characteristics is noticed at the deep surface of the right breast.

mented) healthy contralateral side.

All procedures were performed under general anesthesia. The latissimus dorsi muscular flap was dissected through a small mid-axillary incision and a second further caudally, parallel to the first (Figure 2). The same mid-axillary incision was used for the dissection of the chest pocket into which the latissimus dorsi muscle was transferred.

Implants for the deficient side in female patients were based on preoperative measurements (base width, height). An inframammary incision was used in all patients. Intraoperative examination of the deficient costal cartilages, ribs, pectoralis major, as well as bimanual palpation of the pathological breast was carried out (Figure 3). A fibro adenoma from the deficient breast of a 29-year old patient was excised before augmentation through the same inframammary incision (Figures 1 and 3B). A sizer

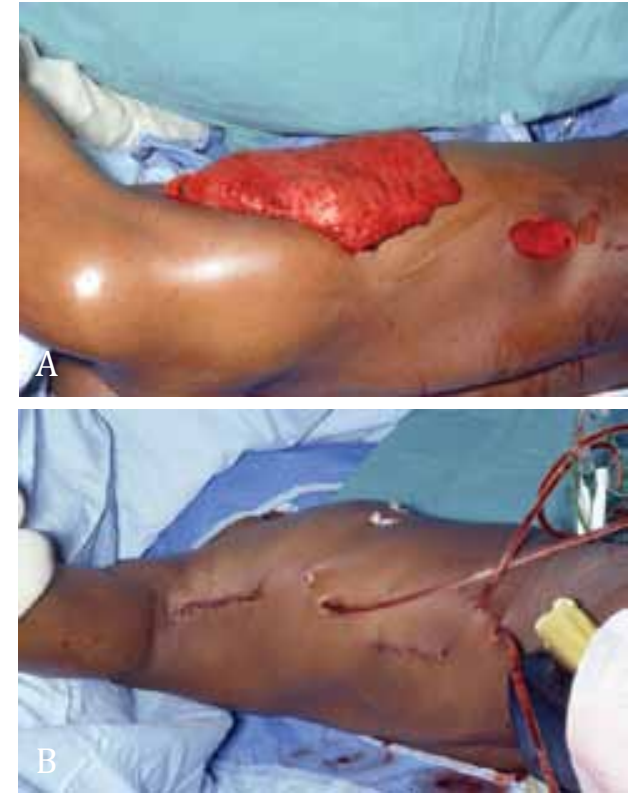

Figure 2. A. Intraoperative view of a male patient with absence of the pectoralis major muscle; the two incisions and the dissected latissimus dorsi muscle are clearly seen. B. Immediate postoperative lateral view of the same patient.
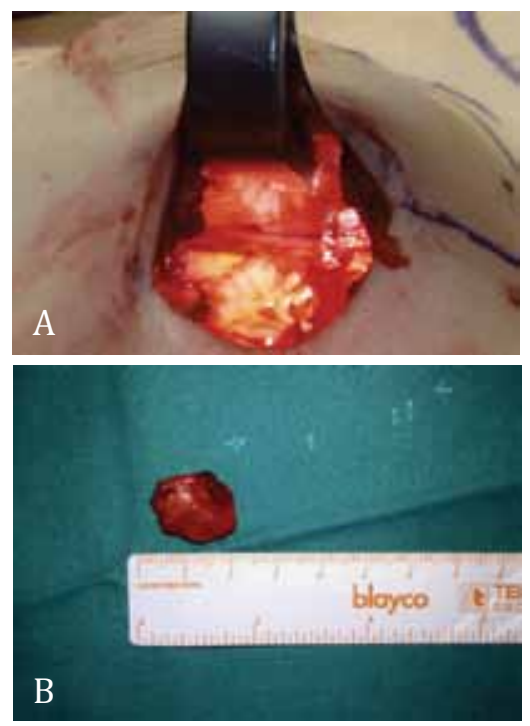

Figure 3. A. Intraoperative view of a female patient; the dissected submammary pocket, the deficient costal cartilages and ribs of the right chest wall are visible. B. A benign neoplasm was palpated, and excised through the same inframammary incision. The neoplasm was histopathologically diagnosed as a fibroadenoma. 
was used to determine the final size of the implant which filled the chest depression and corrected the breast deficiency in accordance to the patient's body type and contralateral breast. In cases of a bilateral augmentation, a smaller implant was inserted in the contralateral (healthy) side; its size was also determined with the aid of a sizer and matched the newly reconstructed pathological breast.

Patients were followed clinically and radiographically at annual intervals to assess chest and breast/ nipple symmetry, breast projection, capsule formation, status of the implants and possible emerging breast pathology (Figure 4).

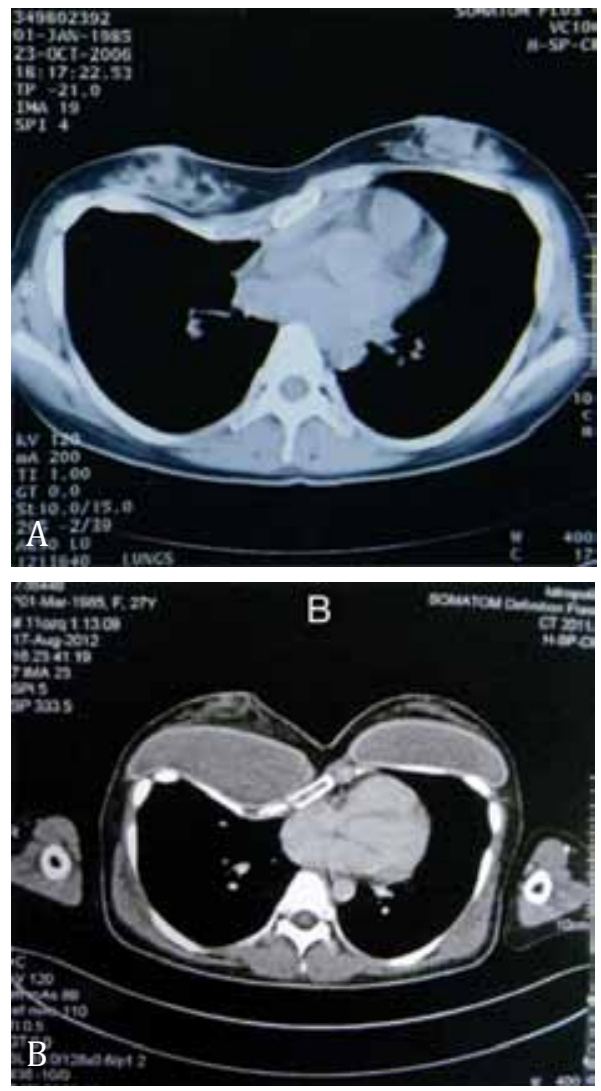

Figure 4. A. Preoperative CT-scan of the chest of a female patient with right Poland syndrome; B. Postoperative CT-scan of the same patient showing the different size of the breast implants and the achieved symmetry.

\section{Results}

Eleven patients presented with a Poland syndrome seeking consultation and eventual correction of their chest and breast deformity (Table 1). One patient had undergone previous hand surgery (syndactyly- age 5) at another institution. Two patients, both females refused to have any surgical reconstruction of the deficient pectoralis muscle (Figure 5). None of them had any other anomalies.

Nine patients underwent surgical correction. There were six females and three males. The age ranged between 21 -29 years (mean 23, 5 years). The right side was affected in eight patients and the left in one. In all males, the pectoralis major muscle was absent, whereas in all females the muscle was hypoplastic, the ribs and costal cartilages were deficient (average thoracic depression volume ca $175 \mathrm{cc}$ ) and the
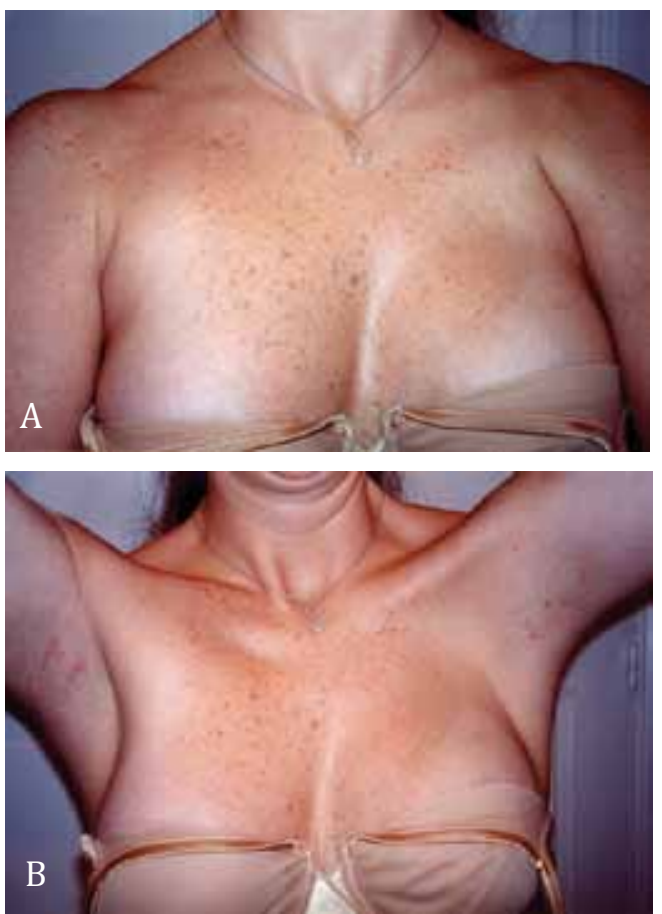

Figure 5. A and B. Female patient with left Poland syndrome; she opted for no treatment. The left pectoralis major muscle deficiency is evident. 
Table 1. Clinical features of the eleven patients

\begin{tabular}{|c|c|c|c|c|c|c|}
\hline PATIENT & SEX & AGE & $\begin{array}{c}\text { SIDE } \\
\text { AFFECTED }\end{array}$ & CHEST/BREAST & OPERATION & COMPLICATIONS \\
\hline 1 & M & 20 & $\mathrm{R}$ & Chest & Lat. dorsi & None \\
\hline 2 & $\mathrm{~F}$ & 22 & $\mathrm{R}$ & Chest + breast & $\begin{array}{l}\text { Augmentation } \\
\text { Mammoplasty }\end{array}$ & None \\
\hline 3 & $\mathrm{~F}$ & 22 & $\mathrm{R}$ & Chest + breast & $\begin{array}{l}\text { Augmentation } \\
\text { Mammoplasty }\end{array}$ & None \\
\hline 4 & M & 20 & $\mathrm{R}$ & Chest & Lat. dorsi & Seroma \\
\hline 5 & $\mathrm{~F}$ & 21 & $\mathrm{R}$ & Chest + breast & $\begin{array}{l}\text { Augmentation } \\
\text { Mammoplasty }\end{array}$ & None \\
\hline 6 & M & 21 & $\mathrm{R}$ & Chest & Lat. dorsi & None \\
\hline 7 & $\mathrm{~F}$ & 20 & LE & Chest + breast & $\begin{array}{l}\text { Augmentation } \\
\text { Mammoplasty }\end{array}$ & None \\
\hline 8 & $\mathrm{~F}$ & 33 & LE & Chest & None & None \\
\hline 9 & $\mathrm{~F}$ & 23 & $\mathrm{Ri}$ & Chest + breast & $\begin{array}{l}\text { Augmentation } \\
\text { Mammoplasty }\end{array}$ & None \\
\hline 10 & $\mathrm{~F}$ & 22 & $\mathrm{Ri}$ & Chest + breast & $\begin{array}{l}\text { Augmentation } \\
\text { Mammoplasty }\end{array}$ & None \\
\hline 11 & $\mathrm{~F}$ & & $\mathrm{LE}$ & Chest & None & None \\
\hline
\end{tabular}

pathological breast was smaller (Figure 6) or had a tubular shape (Figure 7); the nipple/areola complex of the deficient size was smaller (Figure 6) and in a somewhat superior position compared with the contralateral side.

In all three men, the chest wall repair was achieved with a pedicled latissimus dorsi (LD) muscle transfer (Figure 8). Neither microsurgical procedures nor sternal/rib reconstruction were performed. There were no infections and all LD muscle flaps survived. There was one (1/3) small seroma following removal of the donor site suction drain, which resolved without treatment. All patients were satisfied with the outcome.

In women, no LD muscle flap transfer was done. All six underwent a bilateral augmentation mammoplasty through a submammary approach. One type of breast implant was used (Mentor, Siltex Round
Moderate Plus Profile Gel Cohesive). A larger implant with an average fill volume of $325 \mathrm{cc}$ was used for the pathological side, whereas the fill volume for the contralateral side was $137,5 \mathrm{cc}$. There were no complications among the six patients, all of whom were very satisfied with the end result. Nipple/areola complex asymmetry was, partially, corrected (Figure 6) and no patient requested any further operative improvement. No capsular contracture has been detected to date and no revisions were necessary (follow-up period: 2 to 14 years). At follow-up, all patients rated their aesthetic result as good to excellent and all of them admitted to a vast improvement of their self-esteem and self-confidence as a result of the improved, symmetric body image.

\section{Discussion}

Chest wall deformities are classified as: Poland 

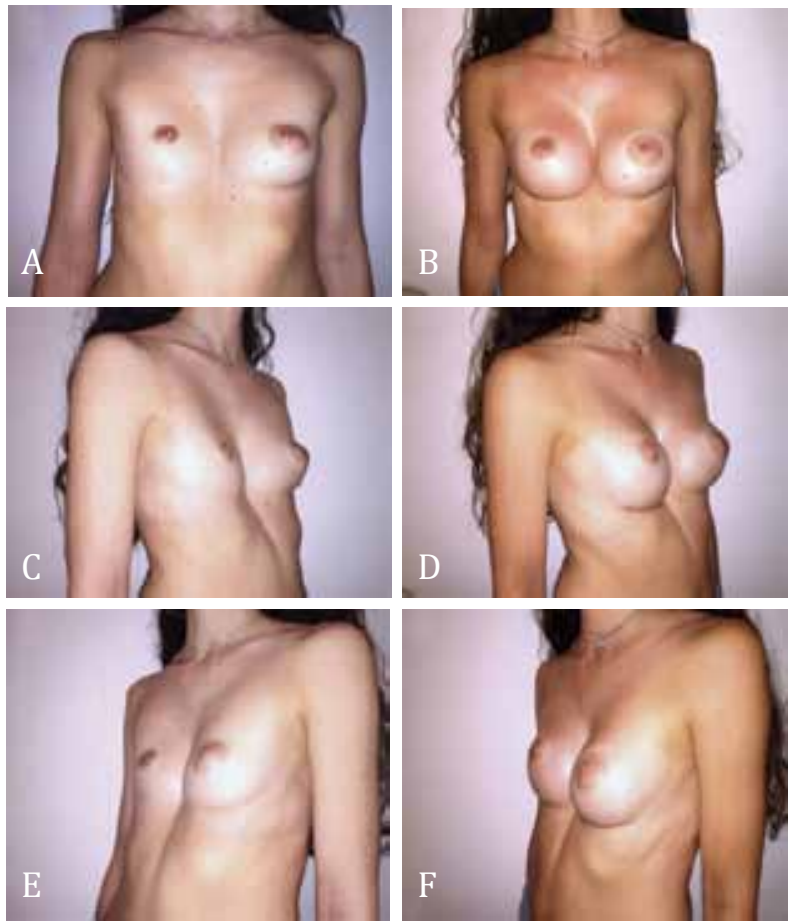

Figure 6. Female patient with right Poland syndrome; the chest wall is deficient and the hypoplastic right breast/ nipple/areola complex accentuates the asymmetry. A and B: Preoperative and postoperative frontal view. C and D: Preoperative and postoperative right oblique view. E and F: Preoperative and postoperative left oblique view 2 years after reconstruction showing a considerable improvement in symmetry of the chest wall, breast and nipple/areola complex. The patient was very satisfied and requested no further surgery.

syndrome, pectus excavatum (funnel chest), pectus carinatum (pigeon chest), defects of sternal fusion and generic skeletal and cartilage dysplasia ${ }^{10}$. Clinicians have long been challenged regarding their diagnosis as well as their reconstruction.

Poland syndrome is a unique unilateral chest/ hand deficiency that may include pectoral muscle deficit, rib defects and brachydactyly/syndactyly. Affected individuals miss partly or completely the sternocostal part of the pectoralis major muscle. Because of this, the anterior axillary line looks underdeveloped. There may also be rib abnormalities
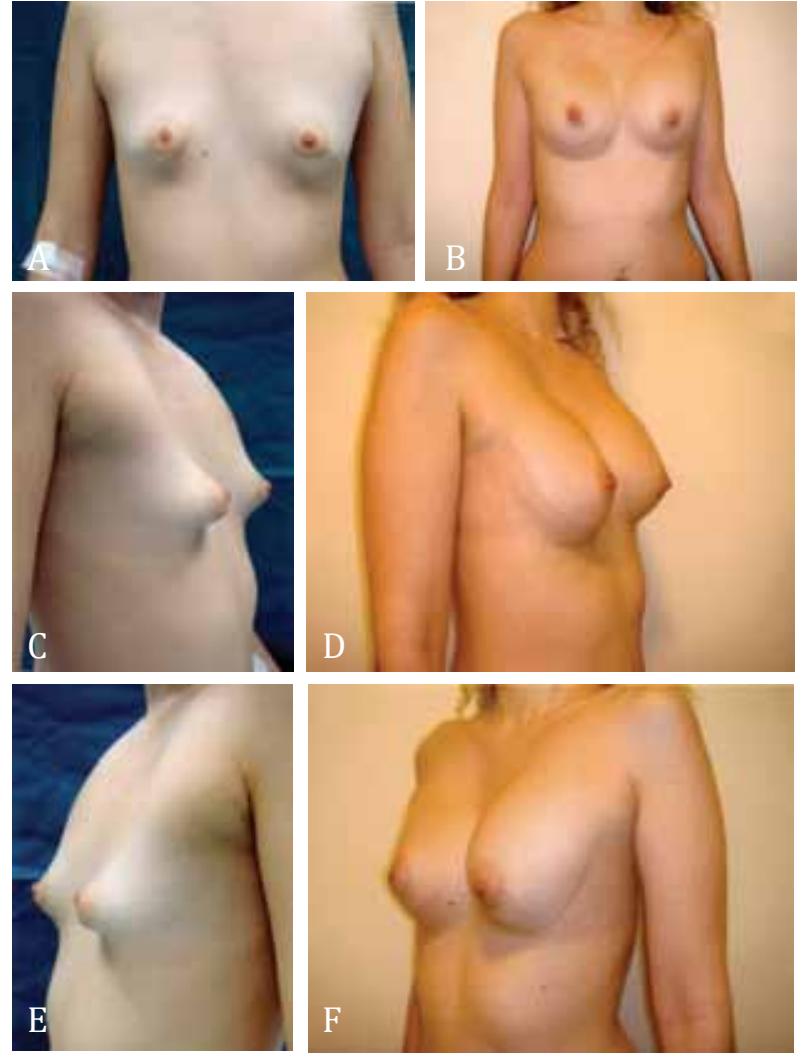

Figure 7. Female patient with right Poland syndrome; there is a clear chest/breast asymmetry. The hypoplastic right breast has a tubular shape. A and B: Preoperative and postoperative frontal view. $\mathrm{C}$ and $\mathrm{D}$ : Preoperative and postoperative right oblique view. E and F: Preoperative and postoperative left oblique view 6 years after reconstruction.

(shortened ribs), costal cartilage abnormalities and an abnormal sternum position. These features may cause the chest to appear concave (depressed). Breast size and shape as well as nipple/areola abnormalities (size, position) may be present. Hypoplasia or aplasia of other muscles (pectoralis minor, serratus anterior, latissimus dorsi, deltoid, external oblique), Sprengel deformity, scoliosis, lung herniation and dextrocardia may also occur ${ }^{8,9,11,12}$. Mild cases of the disease evade detection until late adolescence and puberty, when asymmetry between the right and left side of the body become more apparent. Severely 

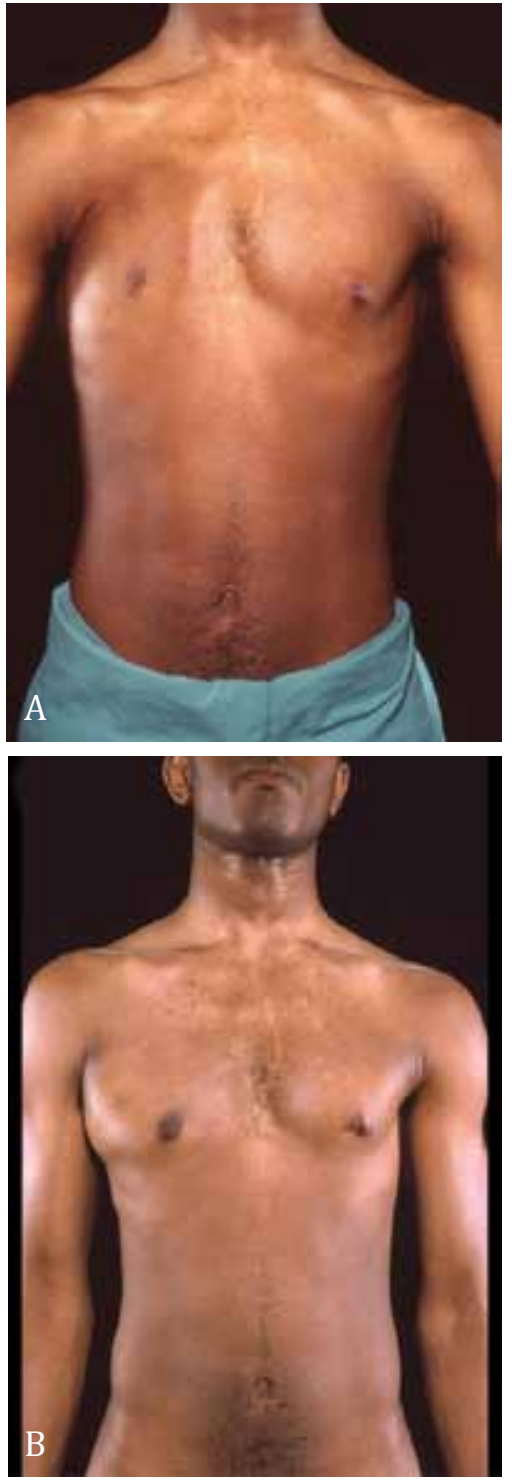

Figure 8. Male patient with right Poland syndrome; there is a considerable chest asymmetry. B. One year after transfer of the right latissimus dorsi muscle in order to replace the absent right pectoralis major muscle. An acceptable symmetry has been achieved.

affected individuals, however, are early diagnosed and existing functional upper limb problems (e.g. syndactyly) are early corrected. The abnormalities of the chest wall are cosmetic in most cases and do not cause health problems or have a negative impact on movement.

Poland syndrome has been estimated to occur in 1 in 20,000 to 100,000 newborns ${ }^{11,13}$. However, due to the inadequacy of reporting, especially of mild cases, the accurate incidence of the disease is unknown. Most cases are sporadic, however, familial occurrence has been reported and the condition seems to be inherited in an autosomal dominant pattern ${ }^{11}$.

The etiology of Poland syndrome has been a matter of debate for many years. To date, three mechanisms of pathogenesis have been described. The first has focused on genetic inheritance. Vaccari et $\mathrm{al}^{14}$ described a couple of monozygotic twin girls, both presenting with Poland syndrome, who carried a de novo heterozygous $126 \mathrm{Kbp}$ deletion at chromosome 11q12.3 involving 5 genes, four of which encode proteins that regulate cellular growth, differentiation, and apoptosis, mainly through Ras-mediated signaling pathways ${ }^{14}$. In a more recent study, a number of copy number variations were identified in patients with Poland syndrome ${ }^{15}$. The authors concluded that the rare inherited copy number variations may contribute, or represent risk factors of Poland syndrome in a multifactorial mode of inheritance ${ }^{15}$. The second hypothesis involves vascular compromise, namely an injury to the subclavian and vertebral arteries and/ or their branches during embryogenesis, resulting in developmental alterations in the areas supplied by the artery ${ }^{11,13}$. This event has been termed subclavian artery supply disruption sequence ${ }^{16}$. The degree of vessel obstruction and the location of vessel involvement define the ensuing musculoskeletal malformations ${ }^{13,16}$. The third, and last, hypothesis involves environmental factors (e.g. smoking) ${ }^{17}$, however no follow-up work has been presented in the literature since the original study ${ }^{13}$.

The literature indicates that the right side is more frequently affected, furthermore there seems to be a predilection for the syndrome in male subjects ${ }^{4,18}$. Several studies showed, however, that the number of 
operated female patients vastly exceeds that of male patients ${ }^{19-21}$ in accordance with the results of the present study. An explanation was given by Ram and Chung ${ }^{13}$ who postulated that irregular or asymmetric breast growth tends to be noticed more by females during late adolescence and puberty and prompts them to seek treatment. On the other hand, male patients who experience asymmetric chest growth typically do not seek treatment as readily or not at $\mathrm{all}^{13}$. Severe cases with apparent hand and arm abnormalities are diagnosed and treated early in life ${ }^{9}$.

The accurate clinical diagnosis of Poland syndrome requires a thorough, comparative, undraped evaluation of the two halves of the torso and both upper extremities. Inspection, palpation and, eventually, measurements of both sides are performed. Standard muscle testing is carried out and photographs are obtained. When patients opt for an operative correction, we routinely perform a thorax/breast MRI, which defines musculoskeletal and associated anatomy and aids preoperative planning without the burden of ionizing radiation ${ }^{22}$. Other imaging modalities (U/S, mammography, CT scan, color Doppler U/S) have been used by various authors in selected cases ${ }^{4}$.

Surgical correction of the chest, breast and nipple/ areola complex deformity is basically cosmetic. Very seldom, the indication is functional impairment (e.g. weakness) of the collateral upper extremity ${ }^{23}$. The missing pectoralis major is replaced with a pedicled latissimus dorsi muscular flap ${ }^{4,7,19,20}$. The latter is used mainly in male patients, and less often in females in association with breast implants. It is commonly considered the 'gold standard' for those patients who have achieved complete clinical growth ${ }^{7}$. Because the muscle originates, like the pectoralis major, from a median structure, the insert of the humerus, and both are adductors and medial rotators of the humerus, no reeducation is required after transfer. Some patients have reported a postoperative improvement when performing pushups and weight training ${ }^{4}$. The entire muscle is transferred and although there is usually no functional impairment (no patient in the current study experienced any problem), the patients ought to be informed of the possibility of difficulties in sports and art activities, limitation of shoulder motion and shoulder strength weakness over time ${ }^{24}$. This is the reason, why some authors consider the latissimus dorsi transposition in young patients with Poland syndrome an inappropriate surgical procedure, especially considering possible hypoplasia of the latissimus dorsi and potential postural problems resulting from the abnormalities of the syndrome ${ }^{7}$. Other authors, however, did not hesitate to transfer the lat. dorsi in a 15-year old boy with Poland syndrome and severe pectus excavatum, combined with a Fonkalsrud procedure (costal cartilage-sparing version of the modified Ravitch procedure) in order to repair the chest deformity. The outcome of the combined procedure was reported to be successful ${ }^{25}$.

Chest deficiency and breast deformity in female patients, particularly when the sternocostal head of the pectoralis major is hypoplastic and not absent can be satisfactorily treated with a mammary prosthesis. Adjuncts to the mammary prosthesis, whenever indicated, include a lat. dorsi muscle transfer, a transverse rectus abdominis muscle flap (TRAM flap), a customized chest wall implant, and fat grafting, all of which improve the shape and volume of the deficient chest wall ${ }^{4,5,26-28}$. Hodgkinson ${ }^{28}$ supported the notion, that a combination of a customized solid silicone implant, to correct the chest wall depression, with a mammary prosthesis is necessary in order to achieve a satisfactory result. The results of previous ${ }^{4,29}$ as well as these of the current study, however, show that a mammary prosthesis alone can satisfactorily fill the chest wall depression and restore the shape and volume of the breast. Customized solid implants, although a tempting alternative (or an adjunct), often have to be removed because of patient complaints of migration, discomfort, pain, 
and contour irregularities ${ }^{4,30}$. It is interesting to note that all four solid chest wall prostheses placed by Seyfer et $\mathrm{al}^{4}$ were removed because of one of the aforementioned reasons. Other authors, like Chavoin et $\mathrm{al}^{31}$, have reported satisfactory results using a computer-aided custom design silicone implant. In $24 \%$ of the cases, these authors used breast implants as well. More than $80 \%$ of the 129 treated patients were satisfied, with no significant difference between men and women ${ }^{31}$.

An alternative method to restore the contour of the chest and breast is a microvascular free flap. It is not routinely applied; a few authors have used a free TRAM, a deep inferior epigastric artery perforator (DIEP), a gluteal artery perforator (GAP) or an anterolateral thigh (ALT) flap in selected patients ${ }^{26,32,33}$. Use of microvascular techniques, duration of the operation, longer recovery period and higher costs are some of the disadvantages of free flaps. On the other hand, it is probably the method of choice in selected patients who do not wish to have foreign material.

Autologous fat injection, either alone or more often in combination with other reconstruction techniques, has also been reported ${ }^{34,35}$. Absorption of free fat and the number of sessions (2-5) is a drawback of this method. Del Vecchio and Bucky postulated that long lasting results can be achieved, especially when placing the fat after pre-expansion of the breast $\mathrm{t}^{35}$.

The size and shape of the nipple-areola complex improves after placement of the lat. dorsi muscle and/or the breast implant in the pathologic side, as was shown in this study (Figure 6). No patient of ours requested any further corrections. However, occasionally adjustments or further surgical translocation of the nipple-areola complex (NAC) may be indicated ${ }^{4,5}$. These can be easily performed at a later stage under local anesthesia. Romanini et $\mathrm{al}^{5}$ preferred to perform a two-stage correction of the NAC in cases of hypoplasia and dislocation of $>2 \mathrm{~cm}$
(N2). In the first instance they used a tissue expander and at a later stage they placed the implant and/or a fat graft ${ }^{5}$. In cases of absence of the NAC (N3), a total nipple areola reconstruction is indicated.

Most studies report contralateral breast surgery in a considerable number of patients. The vast majority, over $95 \%$ of them, are women ${ }^{4,20}$. These procedures on the unaffected side ameliorate asymmetry and improve the body image. All six female patients of this study had a contralateral breast procedure (augmentation/mastopexy) and all were very satisfied with the outcome. This finding is in accordance with the results reported in the literature.

Timing of any operative correction has been a matter of debate. A recent study by Baldelli et $\mathrm{al}^{7}$ showed that patients with Poland syndrome experience maximum psychological discomfort during adolescence. A nonhealthy body perception, insecurities and finally a body image disorder may stabilize, which is difficult to improve even with surgery. Hence, the authors postulated that less invasive, multistage surgery (autologous fat grafting, tissue expanders, implants) starting at an early age is indicated. Their clinical results showed that surgical correction during the teen years may have a positive impact on stabilization of the body image and quality of life of young patients. Whether using the less invasive approach with more stages provides a better aesthetic result, based on objective measurements, compared with that obtained using the standard surgical approach is a question to be answered by a future study ${ }^{7}$. Seyfer et $\mathrm{al}^{4}$, however, prefer to delay most of these procedures until late adolescence or adulthood. Their arguments for waiting are: 1 . Growth inhibition if operative trauma is administered too early. 2. Necessity for revision procedures to keep pace with growth after early repair. 3 . The right of the patient to participate in competent decisions affecting her or his own body. 4. Patient's informed consent, which only older individuals can reliably 
provide 4 . All patients of our small case series happened to be young adults. If, however, adolescents seek surgical aid because of serious psychological problems, early surgery should not be a priori excluded. The alternatives, their risks, complications and possible short- and long term sequelae are discussed in detail with them and their parents and informed consent of the parents is obtained. Young age is not an absolute contraindication for cosmetic chest/breast surgery, however, growth changes and possible resulting problems should always be taken into account.

Fekih et $\mathrm{al}^{36}$ stated that the simplest and the fastest correction technique, the one with the least complications and cosmetic sequelae and the most practiced by the surgeon, remains the best method for breast anomaly correction of Poland's syndrome. We basically agree with their view, however, we would like to amend one or two points. Plastic surgeons should be comfortable with all available techniques and should select the procedure which will achieve the best result for the individual patient with the least complications and which will alter the patient's body image drastically improving their self-esteem and quality of life. All other medical specialists (general practitioners, pediatricians, gynecologists, thoracic surgeons etc.), if and when consulted with regard to Poland syndrome, should be fully aware of the surgical options and especially of the timing surgery ought to take place, in order to better guide their patients.

\section{Conclusion}

Poland syndrome encompasses a wide spectrum of upper extremity, chest and breast anomalies. From the wide selection of surgical procedures, latissimus dorsi muscle transposition can be regarded as the 'gold standard' for correction of cosmetic chest deficiency especially in male patients. Breast implants satisfactorily correct deficient breast shape and size in most female patients. Minor secondary correc- tions of the nipple/areola complex are occasionally indicated in order to optimize the outcome. Surgery aims at improving the patient's self-esteem and quality of life; therefore its timing should be patientdependent and should be defined according to the individual patient's needs.

\section{References}

1. Poland A: Deficiency of the pectoralis muscles. Guys Hosp Rep 1841; 6:191-93.

2. Clarkson P: Poland's syndactyly. Guys Hosp Rep 1962; 111:335-46.

3. Baudinne P, Bovy GL, Wasterlain A: [A case of Poland's syndrome] (in French). Acta Paediatr Belg 1967; 21:407-10.

4. Seyfer AE, Fox JP, Hamilton CG: Poland syndrome: Evaluation and treatment of the chest wall in 63 patients. Plast Reconstr Surg 2010; 126:902-11.

5. Romanini MV, Torre M, Santi P et al: Proposal of TBN classification of thoracic anomalies and treatment algorithm for Poland syndrome. Plast Reconstr Surg 2016; 138:50-8.

6. Senrui H, Egawa T, Horiki A: Anatomical findings in the hands of patients with Poland's syndrome. J Bone Joint Surg (Am) 1982; 64:1079-82.

7. Baldelli I, Santi P, Dova L et al: Body image disorders and surgical timing in patients affected by Poland syndrome: Data analysis of 58 cases. Plast Reconstr Surg 2016; 137: 1273-82.

8. Pegorier 0, Watier E, Leveque J et al: [Breast reconstruction in Poland syndrome. A propos of 9 cases]. Ann Chir Plast Esthet 1994; 39: 211-8 ; discussion 219-20.

9. Buckwalter JA, Shah AS: Presentation and treatment of Poland anomaly. Hand 2016; 11: 389-95.

10. Marks MW, Iacobucci J: Reconstruction of congenital wall deformities using solid silicone onlay prostheses. Chest Surg Clin North Am 2000; 10: 341-55.

11. Poland syndrome: National Institute of Health-Genetics Home Reference. Available at: http/www. 
ghr.nlm.gov/condition/poland -syndrome \# inheritance. Accessed 2 Oct 2019.

12. Yiyit N, Isitmangil T, Oksuez S: Clinical analysis of 113 patients with Poland syndrome. Ann Thorac Surg 2015; 99: 999-1004.

13. Ram AN, Chung KC: Poland's syndrome: Current thoughts in the setting of a controversy. Plast Reconstr Surg 2009; 123: 949-53.

14. Vaccari CM, Romanini MV, Musante I et al: De novo deletion of chromosome 11q12.3 in monozygotic twins affected by Poland syndrome. BMC Med Genet 2014; 15: 63.

15. Vaccari CM, Tassano E, Torre $\mathrm{M}$ et al: Assessment of copy number variations in 120 patients with Poland syndrome. BMC Med Genet 2016; 17: 89.

16. Bavinck JN, Weaver DD: Subclavian artery supply disruption sequence: hypothesis of a vascular etiology for Poland, Klippel-Feil, and Moebius anomalies. Am J Med Genet 1986; 23: 903-18.

17. Martinez-Frias ML, Czeizel AE, Rodriguez-Pinilla $E$ et al: Smoking during pregnancy and Poland sequence: results of a population-based registry and a case control registry. Teratology 1999; 59: 35-8.

18. Frioui S, Khachnaoui F: Poland's syndrome. Pan Afr Med J 2015; 21: 294.

19. Freitas Rda S, Tolazzi AR, Martins VD et al: Poland's syndrome: different clinical presentations and surgical reconstructions in 18 cases. Aesthet Plast Surg 2007; 31: 140-6.

20. Majdak-Paredes EJ, Shafighi M, Fatah F: Integrated algorithm for reconstruction of complex forms of Poland syndrome: 20-year outcomes. J Plast Reconstr Aesthet Surg 2015; 68: 1386-94.

21. Manzano Surroca M, Parri F, Tarrado X: Poland sequence: Retrospective analysis of 66 cases. Ann Plast Surg 2019; 82: 499-511.

22. Wright AR, Milner RH, Bainbridge LC et al: MR and CT in the assessment of Poland syndrome. J Comput Assist Tomogr 1992; 16: 442-7.

23. Buchanan P, Leyngold M, Mast BA: Bipolar latis- simus dorsi transfer for restoration of pectoralis major function in Poland syndrome. Ann Plast Surg 2016; 77: 85-9.

24. Lee KT, Mun GH: A systematic review of functional donor-site morbidity after latissimus dorsi muscle transfer. Plast Reconstr Surg 2014; 134: 303-14.

25. Dingeldein MW, Lu CY, Kim AW et al: Simultaneous costal cartilage-sparing modified Ravitch procedure and latissimus dorsi transfer for chest wall deformity repair in Poland's syndrome. J Pediatr Surg 2009; 44: e29-32.

26. Longaker MT, Glat PM, Colen LB et al: Reconstruction of breast asymmetry in Poland's chest wall deformity using microvascular free flaps. Plast Reconstr Surg 1999; 99: 429-36.

27. Baratte A, Bodin F, Del Pin D et al: [Poland's syndrome in women: Therapeutic indications according to the grade. A propos of 11 cases and review of the literature]. Ann Chir Plast Esthet 2011; 56: 33-42.

28. Hodgkinson DJ: Anterior thoracic hypoplasia: a separate entity from Poland's syndrome. Plast Reconstr Surg 2005; 115: 960-1.

29. Spear SL, Pelletiere CV, Lee ES et al: Anterior thoracic hypoplasia: A separate entity from Poland syndrome. Plast Reconstr Surg 2004; 113: 69-77.

30. Spear SL: Anterior thoracic hypoplasia: A separate entity from Poland syndrome. Reply. Plast Reconstr Surg 2005; 15: 961-2.

31. Chavoin JP, Taizou M, Moreno B et al: Correcting Poland syndrome with a custom made silicone implant: Contribution of three-dimensional computer aided design reconstruction. Plast Reconstr Surg 2018; 142: 109e-119e.

32. Granzow JW, Levine JL, Chiu ES et al: Breast reconstruction using perforator flaps. J Surg Oncol 2006; 94: 441-54.

33. Dolas SC, Poovamma CU, Prema M et al: Poland's syndrome: a case report with review of the literature regarding management. Breast Dis 2014; 
34: 121-5.

34. Pinsolle V, Chichery A, Grolleau JL et al: Autologous fat injection in Poland's syndrome. J Plast Reconstr Aesthet Surg 2008; 61: 784-91.

35. Del Vecchio DA, Bucky LP: Breast augmentation using preexpansion and autologous fat transplantation: a clinical and radiographic study. Plast Reconstr Surg 2011; 127: 2441-50.

36. Fekih M, Mansouri-Hattab N, Bergaoui D et al: [Correction of breast Poland's anomalies. About eight cases and literature review]. Ann Chir Plast Esthet 2010; 55: 211-8.
Received 24-02-20

Revised 04-05-20

Accepted 19-05-20 